\title{
Influence of coke structure on coke quality using image analysis method
}

\author{
B. Ghosh $^{1} \cdot$ B. K. Sahoo ${ }^{1}$ B. Chakraborty ${ }^{1} \cdot$ K. K. Manjhi ${ }^{1}$. S. K. Das ${ }^{1} \cdot$ \\ J. N. Sahu ${ }^{2,4} \cdot$ Atul K. Varma ${ }^{3}$
}

Received: 21 February 2018/Revised: 24 August 2018/Accepted: 1 November 2018/Published online: 22 November 2018

(C) The Author(s) 2018

\begin{abstract}
The quality of coke affects the performance of the blast furnace, factors affecting coke quality include coal properties, coal charge granulometry and carbonization conditions. The coke properties include the size analysis, cold strength (Micum Indices- $\mathrm{M}_{40}, \mathrm{M}_{10}$ ) and hot strength (Coke Reactivity Index-CRI, Coke Strength after Reaction-CSR) properties and structural properties such as coke structure and texture. Structural properties comprise the porosity, pore-cell wall thickness and pore sizes, while textures consist of the carbon forms in the coke. In present work, advanced method such as image analysis method was used to interpret coke microstructure. Conventional methods such as determination of coke porosity by measurement of real and apparent density and mercury porosimetry have a number of limitations. Coke size, magnification, number of image frames captured, process of pellet preparations and coke properties such as $\mathbf{M}_{40}, \mathrm{M}_{10}$, CRI and CSR (low, medium and high values) were taken as variables for experimental purposes. The coke structure parameters such as porosity, length, perimeter, breadth, roundness, pore-wall thickness and pore size distribution of the pores were determined by image analysis method. This method provided average porosity in addition to pore-wall thickness and pore-size distribution. The pore wall thickness measurement by image analysis method provided significant correlations with $\mathrm{M}_{40}$, CRI and CSR values. This explained the usability of image analysis for coke structure measurement.
\end{abstract}

Keywords Image analysis $\cdot$ Coke structure $\cdot$ Porosity $\cdot$ Micro structure $\cdot$ Roundness $\cdot$ Pore wall thickness

\section{Introduction}

Coke is produced by heating finely crushed coal charge in air tight coke ovens. The coal charge mostly consists of blends of different coking coals and in some cases also partially briquetted charge coal. After carbonization, the coke is pushed from the ovens and quenched with water/ inert gas (dry quenching). This hard and porous carbonaceous product acts mainly as a source of reductant for the reduction of iron ore, provides thermal energy and provides a permeable support for the burden materials in the blast furnace. Although coke is expensive, it is still indispensable for the production of liquid iron through Blast Furnace (BF) route. The Major functions of coke in $\mathrm{BF}$ are to provide heat for different endothermic reactions inside the $\mathrm{BF}$ and for melting of slag and metal, reducing gases required for the reduction of iron oxides, support and permeable bed during counter current flow of materials and 
gases in BF. Coke is the only solid material in the furnace that supports the iron bearing burden and provides a permeable bed necessary for slag and metal to pass down into the hearth and for hot gases to pass upwards in BF. Of the above mentioned three roles of BF coke, the first two can be substituted by oil, gas, plastics and non-coking coals. These are injected through tuyeres to generate heat and reducing gases. Such a substitution brings reduction in coke rates for the blast furnace (coke rate is the weight of coke required to produce one tonne of hot metal). However, there is no other satisfactory material available, which can replace, fully or partially, metallurgical coke as a permeable support of blast furnace charge materials (burden). Over the last few decades, coke quality requirements have become more stringent due to development of large capacity blast furnaces $\left(>3500 \mathrm{~m}^{3}\right)$ and high pulverized coal injection (PCI)/coal dust injection (CDI) rates.

The quality of coke affects the performance of the blast furnace, factors affecting coke quality include coal properties, coal charge granulometry and carbonization conditions. Coal properties include the petrographic properties such as maceral composition and rank; the rheological properties such as maximum plasticity, temperature range of plasticity, contraction, dilatation, free swelling and Roga index; the chemical properties such as moisture, ash, volatile and sulphur content and the size analysis of coal. The coke properties comprise the size analysis, the cold strength $\left(\mathrm{M}_{40}, \mathrm{M}_{10}\right)$ and hot strength (CRI, CSR) properties and structural properties such as coke structure and texture. Structural properties consist of the porosity, pore-cell wall and pore sizes, while texture includes the carbon forms in the coke. The relationship between CRI and CSR index was developed for a series of more than 60 cokes produced from straight coals of different rank and geographical origin and from complex coal blends (Fig. 1) (Menendez et al. 1999).

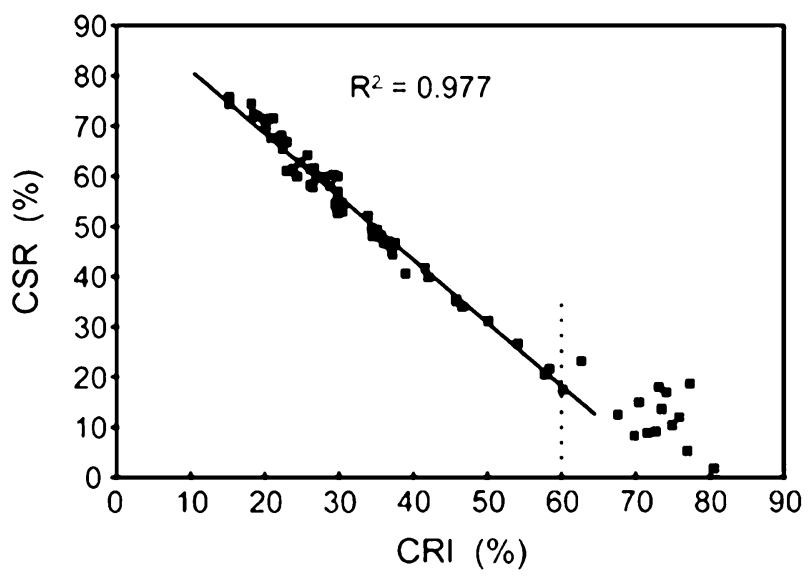

Fig. 1 Relationship between CRI and CSR indices (Menendez et al. 1999)
An extensive literature review was carried out on studies on coke structure by different techniques. The existing literature reveals that most of these research efforts are essentially focused on the image analysis of coke structure, optical texture (Das et al. 2009), porosity determination methods, model prediction to develop correlation etc. as aforesaid. It has been shown that total porosity and pore structure are significant factors affecting coke strength (Donskoi et al. 2013; Grant and Chaklader 1991; Johnson et al. 2013; Karacan and Badger 2003; Xing et al. 2013). It was observed that coke strength is mainly determined by pores and cracks that cause fracturing of coke (Kubota et al. 2011). Moreover, connected pores can cause coke fractures and that coke strength is directly related to the concentration of low roundness pores. It was concluded that the amount of low roundness pores is one of the factors determining coke strength. The coke pore and pore wall micro structure was quantified using image analysis (Andriopoulos et al. 2003; Radlinski et al. 2004). The micro structural features of a good coke included a relatively thick coke wall and a pore size distribution. The reason for cracks in anodes was investigated, as it was important for the quality of the baked anode (Bhattacharyay et al. 2013). In this article, an image analysis technique was described and analyzed as well as quantified the area percentage of pores/cracks and weight percentages of pitch and coke. The microstructure of coke particles can be considered to consist of their optical texture and porosity. Several image analysis techniques were used to determine the size, shape, and orientation of the optical domains in calcined petroleum cokes (Nyathi et al. 2013; Qiao and Eser 1997).

A relationship was developed, which predicts increases in strength with reduction in the number of pores and the pore size and with increasing pore wall size (Patrick and Walker 1989). It was used to estimate the strength of coke from knowledge of the macro-porous structure. The strength of coke largely depends on the thermoplastic and dilatation behavior of its coal constituents. The variation in combination of blended coal was studied (Hayashi et al. 2014). The resulting changes in coke pore structure were investigated by image analysis of a cross-section of coke. The tensile strength of coke was studied to obtain a better understanding of coke strength and its relation to coal properties (Sato et al. 1998). A method for automatic image analysis of coke texture was developed (Eilertsen et al. 1996). This method used an optical polarizing reflecting light microscope, with automatic sample movement. A series of images size $405 \mathrm{~mm} \times 270 \mathrm{~mm}$ was captured using CCD video camera. These images were sub divided into six squares at $135 \mathrm{~mm} \times 135 \mathrm{~mm}$ each. For each of these squares an image displaying the contours of the optical domains was made. Also, automated coke petrography showed good statistical results on the determination 
of the structural property of coke (Eberli et al. 2004; Greeff and Smith 1987; Gupta et al. 2012).

In the present work, cokes made from different coal blends and straight coals with a wide range of properties were examined. Coke is highly porous material, which indicates that coke strength is likely to depend on both the pore wall thickness and pore properties such as porosity, radius, shape, pore size distribution. These pore properties have a strong effect on its strength. It was observed that total porosity is important because high porosity indicated a reduction of strength. Pore shape is also a very important parameter; angular edges pores are more prone to stress concentration. The cold strength parameters of coke such as $\mathrm{M}_{40}$ and $\mathrm{M}_{10}$ were determined by Micum drum test. The hot strength parameters of coke such as CRI and CSR were determined in accordance of IS 4023:1991 standards using Kanthal make equipment. The present study was emphasized on importance of coke structures for coke quality. The effects of the porous structure and the coke matrix strength on the hot and cold strength parameters were evaluated. The porous structure of coke such as was porosity, pore wall thickness, roundness and perimeter was observed by means of reflected light optical microscope through image analysis method. A methodology for measurement of coke structure based on image analysis was developed.

\section{Experimental}

\subsection{Materials}

Experiments were carried out for the determination of coke structure using different methods. Three levels (Level-I, Level-II and Level-III) of study were identified for this present work. The identified variables were coke sample size in preparation of pellet, magnification of captured images, process of pellet preparation and range of cold and hot strength properties i.e. low, medium and high. The experimental design for image analysis is given in Table 1 . The individual and blend coal used along with their properties in the tests are shown in Table 2. The coking properties of blend coal are as follows; volatile matter (VM), ash, plastic range (PR) and maximum fluidity (MF) varied from 19.5 to $32.7 \%, 4.1$ to $13.4 \%, 62$ to $96{ }^{\circ} \mathrm{C}$ and 12 to 5114 ddpm, respectively. Total thirteen coke samples were selected for study of coke structure determination. The coke samples produced from pilot coke oven (Fig. 2) and from commercial ovens (Coke Oven Battery number 10, ISP, Burnpur) were analyzed in this study. Coke samples were generated in a $250 \mathrm{~kg}$ pilot coke oven (one side moveable wall and other side fixed wall) at Research and Development Center for Iron and Steel (RDCIS), Ranchi.
Coal charge crushing index was maintained at $81 \pm 1 \%$ and moisture content was maintained at $8 \pm 0.5 \%$. Prepared charge coal of bulk density of $670 \mathrm{~kg} / \mathrm{m}^{3}$ was charged in an electrically heated pilot coke oven $(405 \mathrm{~mm}$ width, $915 \mathrm{~mm}$ length and $1015 \mathrm{~mm}$ height) at $850{ }^{\circ} \mathrm{C}$ charging temperature, carbonation temperature was kept at $1000 \pm 10^{\circ} \mathrm{C}$ and carbonized for $18 \mathrm{~h}$. Coke after carbonization was quenched in the wet process.

The determination of coke structure parameters by the image analysis method included measurements of porosity (vol\%), perimeter, roundness, length and pore wall thickness of the pores (Table 3). Porosity or void fraction is a measure of the void (i.e. empty) spaces in a material. Length corresponds to the Longest Feret measured at 64 angles selected. Perimeter refers to estimated perimeter of feature with compensation for corners. Roundness is a measure of the shape of the feature (Perimeter $\left.{ }^{2} \times 1000\right) /$ $(4 \times \mathrm{P} \times$ area, where P-pixel size). From the experimental analyzed data, it has shown (Table 4 ) that porosity value comes close in 10 mesh and $1000 \times$ magnification to the volumetric method i.e. $48 \%$. But, in case of analyzed data from 10 mesh (sample size) and $1000 \times$ magnification, it has covered lower total area and total perimeters than the analyzed data from minus 18 mesh (sample size) and $500 \times$ magnification. The determination of porosity value in minus 18 mesh and $500 \times$ magnification was also close to the volumetric method. Therefore, in this study keeping in mind in all parameters measures, the sample size of minus 18 mesh and images of $500 \times$ magnification were selected as experimental conditions for image analysis of different coke samples.

\subsection{Image analysis method}

The porous structure of the coke was observed by means of image analysis using reflected light microscope. Polished coke samples (pellet) used for the image analysis method were obtained by mounting about $1 \mathrm{~mm}$ [Minus $18 \mathrm{mesh}$, British Standard (BS)] size particle in an impregnated resin and prepared polish section. The image analysis system was programmed to give measurement of the total numbers of pores, porosity (vol\%), length, breadth, roundness, perimeter and pore wall thickness (Fig. 3a).

\subsubsection{Principle}

The image analysis system was used to grab and analyze images for coke micro-structures and optical textures under reflected light microscope with oil immersion objectives rapidly and accurately. The system was comprised of color digital camera, interfaces, software, data acquisition and other required equipments. The image analysis software was used for processing, display and analysis of color or 
Table 1 The experimental design for image analysis

\begin{tabular}{|c|c|c|c|c|c|}
\hline $\begin{array}{l}\text { Sl. } \\
\text { no. }\end{array}$ & Variable & Level-I & Level-II & Level-III & Selection \\
\hline 1 & $\begin{array}{l}\text { Preparation of pellet (coke sample } \\
\text { size) }\end{array}$ & $\begin{array}{l}\text { BS6 mesh } \\
\quad(2.80 \mathrm{~mm})\end{array}$ & $\begin{array}{l}\text { BS10 mesh } \\
\quad(1.70 \mathrm{~mm})\end{array}$ & $\begin{array}{l}\text { BS18 mesh } \\
\quad(0.85 \mathrm{~mm})\end{array}$ & $\begin{array}{l}\text { BS18 mesh } \\
\quad(0.85 \mathrm{~mm})\end{array}$ \\
\hline 2 & Magnification & $1000 \times$ & $500 \times$ & $320 \times$ & $500 \times$ \\
\hline 3 & No. of frames captured & $20 * 3$ & $20 * 2$ & 20 & 20 \\
\hline 4 & Process of pellet preparations & Resin-1 & Resin-1 & Resin-2 & Resin-1 \\
\hline \multirow[t]{5}{*}{5} & Coke properties & & & & \\
\hline & $\mathrm{M}_{40}$ & Low & Medium & High & All levels \\
\hline & $\mathrm{M}_{10}$ & Low & Medium & High & All levels \\
\hline & CRI & Low & Medium & High & All levels \\
\hline & CSR & Low & Medium & High & All levels \\
\hline
\end{tabular}

Table 2 Properties of coal blends used for generation of coke samples

\begin{tabular}{|c|c|c|c|c|c|}
\hline $\begin{array}{l}\text { Sample } \\
\text { number }\end{array}$ & $\begin{array}{l}\text { Analytical moisture (AM) } \\
(\%)\end{array}$ & $\begin{array}{l}\text { Volatile matter (VM) } \\
(\%)\end{array}$ & Ash content (\%) & $\begin{array}{l}\text { Plastic range } \\
\left({ }^{\circ} \mathrm{C}\right)\end{array}$ & $\begin{array}{l}\text { Maximum fluidity } \\
\text { (DDPM) }\end{array}$ \\
\hline A1 & 2.0 & 21.6 & 12.6 & 66 & 49 \\
\hline $\mathrm{A} 2$ & 1.0 & 19.5 & 10.6 & 68 & 243 \\
\hline A3 & 1.6 & 21.2 & 9.2 & 75 & 303 \\
\hline A4 & 1.2 & 22.8 & 10.6 & 87 & 765 \\
\hline A5 & 1.9 & 31.2 & 7.9 & 84 & 5114 \\
\hline A6 & 1.3 & 23.6 & 12.9 & 69 & 55 \\
\hline A7 & 1.1 & 21.8 & 8.5 & 81 & 168 \\
\hline A8 & 1.5 & 23.6 & 9.8 & 66 & 1388 \\
\hline A9 & 1.3 & 23.3 & 11.4 & 96 & 201 \\
\hline A10 & 3.7 & 32.7 & 4.1 & 62 & 14 \\
\hline A11 & 1.8 & 24.2 & 12.9 & 66 & 44 \\
\hline A12 & 1.2 & 23.2 & 13.4 & 66 & 12 \\
\hline A13 & 2.5 & 25.1 & 10.5 & 72 & 202 \\
\hline
\end{tabular}

monochrome images of different constituent phases, measurement of dimensions and estimation of gray level and color of different phases present. It was also be capable of carrying out statistical analysis of data.

\subsubsection{Equipment description}

(i) Color digital camera High-resolution color digital camera (5.0 million pixels) for capturing images of coke microstructures and textures. Color depth of the images was of 64 bits. The camera has Peltier cooling element for effective reduction of thermal noise. Signal to noise ratio was of 1000:1. (ii) Interfaces All required interfaces; including optical C-mount adapter, FireWire interface and PCI interface card was supplied. PCI data transfer rates to be about $132 \mathrm{MB} / \mathrm{s}$. (iii) Software Image processing software of Leica Qwin was used to capture images online, store and analyze. It has facilities for calibration measurement according to lens configuration. (iv) Data acquisition system This was comprised of a Personal Computer and printer having following configuration Processor-Intel 4th generation I3 generation processor, speed 3.4 GHz, co-processor in-built, RAM 2 GB (DDR3), hard disk 80 GB, Win XP and Office XP preloaded and back-up in CD, PCI slot, CD-re-writer, video card, 17 inch color monitor, key board, optical mouse, high quality laser jet printer and UPS.

An optical image was obtained by a microscope (Leica DM 4500P) from which a reflected image of a polished coke pellet is converted to an electronic image through a camera. The amplitude of the electrical pulses of the electronic image is a function of the light intensities of grey 

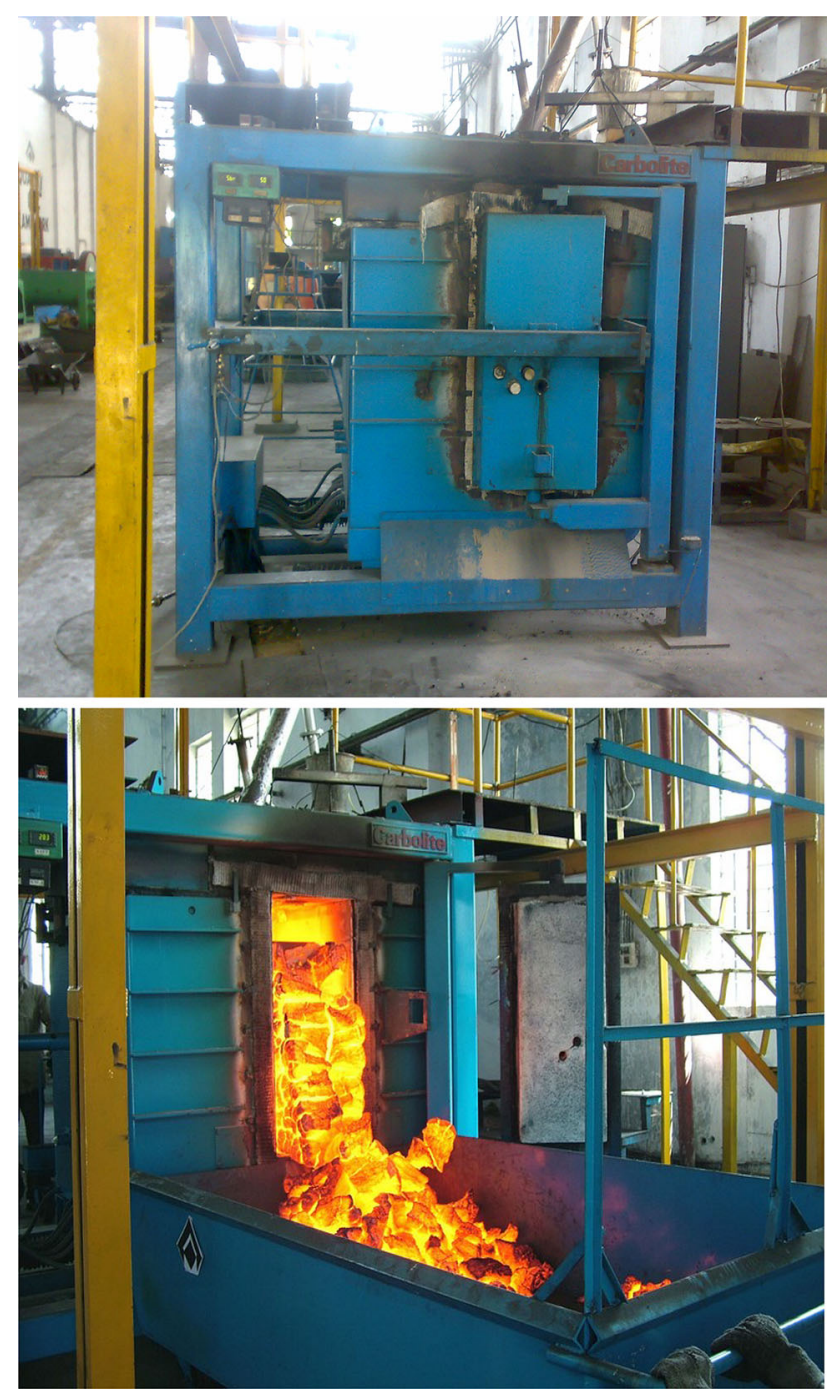

Fig. 2 Photograph of $250 \mathrm{~kg}$ pilot coke oven

levels, determined by the reflectance of the different phases in the optical image. An analogue of the electronic image is transmitted to a discriminator, which contains a densitometer where the image is divided into a matrix of approximately 400,000 picture points on a hexagonal point raster. Each of these points consists of an electrical signal. The densitometer divides the amplitudes of the electrical signal into intervals of grey level bands on a grey scale with 100 intervals. The grey spectrum is adjustable according to the brightness of the image. Operations such as stage movement, data processing, measurement of variable field data are done automatically (Fig. 3b).

\subsubsection{Sample preparation}

Coke is a rather heterogeneous substance owing to the different macerals present in the coal, differences between individual coals in a blend and varying carbonization condition. A relatively large sample therefore was needed for the purpose of sampling, preparation and measurement. A representative sample of $25 \mathrm{~kg}$ coke was progressively crushed down $(-21 \mathrm{~mm}+19 \mathrm{~mm})$ from which a representative sample for determination CRI and CSR of coke, and approximately $8-10$ pieces was used for preparation of pellet for image analysis. Then, these pieces were crushed and passed through about $1 \mathrm{~mm}$ (Minus 18 mesh) screen and mounted in epoxy to eliminate internal reflections. Thereafter, samples were polished on a velvet cloth and slurry of water and alumina.

\subsubsection{Measuring procedure}

A microscope image of the polished surface with a $50 \times$ objective and $10 \times$ condenser lens data field was used for measurement. The polished coke pellets $(2.5 \mathrm{~cm} \times 2.5 \mathrm{~cm})$ were studied using Leica Orthoplan DM4500P polarized reflected light microscope using $50 \times$ oil immersion objective. The images were collected at a standard resolution of $1920 \times 2560$ pixels using Leica DFC-480, 5 Megapixel CCD camera feeding by the Leica Qwin image analysis software. Grey scale images were segmented into binary images using grey scale threshold routine to identify the coke structures such as porosity, pore size distribution, pore wall thickness, roundness and perimeter. The intensity of illuminations of the microscope was set according to the brightness and calibrated in relation to the measurement. The stepping stage was programmed to shift $0.5 \mathrm{~mm}$ horizontally. About 20 fields were taken for a single sample. The repeatability has been studied for coke samples A1 and A11. Repeated determinations was done to cover the same numbers of fields on the same coke samples and shows that the mean value obtained are in a good agreement within $1 \%$ ranges. The details of coke properties and porosity values measured by different methods are given in Tables 5 and 6.

\section{Results and discussion}

Reliable and representative characterization of those aspects of coke structure that are pertinent to some coke quality consideration can be achieved by means of reflected light microscopy coupled with a computerized image analysis system. Special care should be taken for sampling of coke sample for pellet preparation and its polishing. The industrial significances of these measurements in this relationship to such coke properties are strength and reactivity. Coke's porous structure is a function of both the materials carbonized and the conditions of carbonization and aim of this work was to determine the qualitative influence of some of these factors with a view to use such 
Table 3 Schematic diagram for coke structure parameters description

\begin{tabular}{|c|c|c|}
\hline Parameter & Schematic presentation & Description \\
\hline Porosity (\%) & & $\begin{array}{l}\text { A pixel count of the total area occupied by pores } \\
\text { and the total field area of the image is } \\
\text { determined. The ratio of the two givens the } \\
\text { sample porosity }\end{array}$ \\
\hline Perimeter $(\mu \mathrm{m})$ & & $\begin{array}{l}\text { The total length of the boundary around the } \\
\text { detected image within the measure frame }\end{array}$ \\
\hline Roundness & Surrounding circle & $\begin{array}{l}\text { A measure of the shape of the feature Perimeter } \\
2 \times 1000 /(4 \times \mathrm{P} \times \text { Area }) . \mathrm{P}=\text { pixel size }\end{array}$ \\
\hline Length $(\mu \mathrm{m})$ & & $\begin{array}{l}\text { Corresponds to the longest Feret measured at } 8 \text {, } \\
32 \text { or } 64 \text { angles as selected }\end{array}$ \\
\hline Mean pore wall thickness $(\mu \mathrm{m})$ & & $\begin{array}{l}\text { From the edge to the centre of a coke wall, the } \\
\text { grey scale changes as a function of distance. } \\
\text { Centerlines, as indicated in the figure, are } \\
\text { obtained using maximum grayscale values. } \\
\text { Wall thickness is determined from centerline } \\
\text { value using a calibration curve }\end{array}$ \\
\hline
\end{tabular}

data for the specific structural characterization. The nature of the coal charge is obviously a major factor in determining the coke structure and in general, low rank high volatile coals with sufficient fluidity to ensure that all components are fused together tend to produce high porosity cokes. 
Table 4 Selection of size of coke for preparation of coke pellet number A11

\begin{tabular}{llccccc}
\hline S1. no. & Sample size (ASTM) & Magnification & Total area $\left(\mu \mathrm{m}^{2}\right)$ & Total length $(\mu \mathrm{m})$ & Total perimeter $(\mu \mathrm{m})$ & Porosity $(\%)$ \\
\hline 1 & BS10 & $500 \times$ & 94,343 & 34,334 & 131,544 & 49.2 \\
2 & BS10 & $1000 \times$ & 30,944 & 18,156 & 71,015 & 47.4 \\
3 & BS6 & $500 \times$ & 113,834 & 42,770 & 177,450 & 44.8 \\
4 & BS18 & $500 \times$ & 176,895 & 51,896 & 229,809 & 46.7 \\
\hline
\end{tabular}
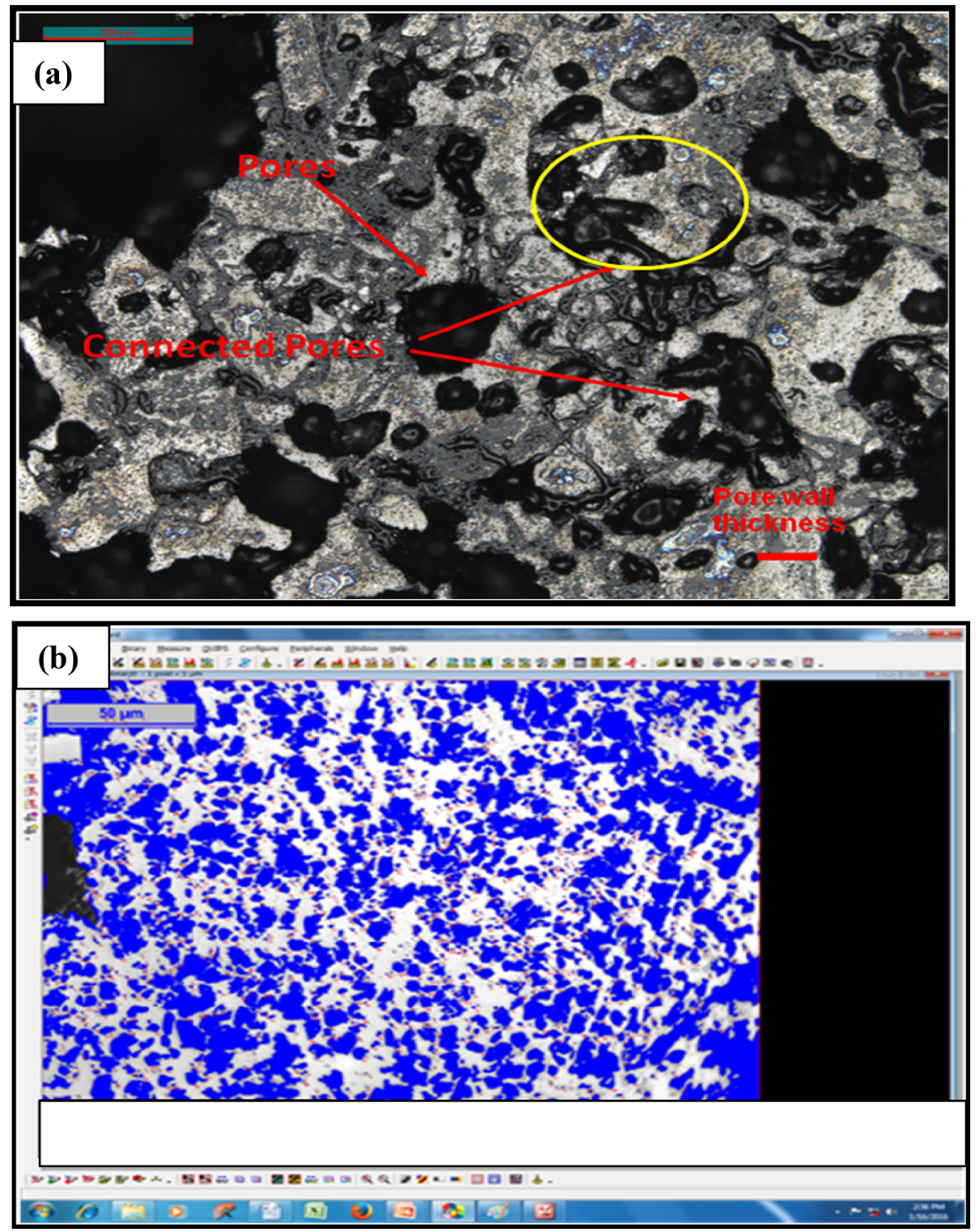

Fig. 3 a Microphotographs showing structure of cokes, $\mathbf{b}$ image analysis methodology showing pore distribution in coke samples

\subsection{Coke structure analysis by image analysis method}

Coke sample produced from the individual straight and blend coals were taken for this study. The properties in the blend coal were varying in analytical moisture, volatile matter, ash content, plastic range and maximum fluidity and different coking properties (Table 2). The pilot coke oven carbonization tests were carried out at RDCIS, SAIL, Ranchi except one coke sample. The selected samples were 
Table 5 Comparison of porosity values determined by different methods and properties of coke samples

\begin{tabular}{|c|c|c|c|c|c|c|c|c|c|}
\hline \multirow{2}{*}{$\begin{array}{l}\text { Sample } \\
\text { number }\end{array}$} & \multirow{2}{*}{$\begin{array}{l}\text { Volumetric method } \\
\text { (Vol\%) }\end{array}$} & \multirow{2}{*}{$\begin{array}{l}\text { Image analysis } \\
(\text { Vol\%) }\end{array}$} & \multirow{2}{*}{$\begin{array}{l}\text { Std. } \\
\text { dev }\end{array}$} & \multirow{2}{*}{$\begin{array}{l}\text { Mercury porosimetry } \\
(\text { Vol\%) }\end{array}$} & \multirow{2}{*}{$\begin{array}{l}\text { X-ray CT scan method } \\
(\text { Vol\%) }\end{array}$} & \multicolumn{4}{|c|}{ Coke properties } \\
\hline & & & & & & $\mathrm{M}_{40}$ & $\mathrm{M}_{10}$ & CRI & CSR \\
\hline A1 & 51.9 & $49.5 / 48.5$ & 9.9 & 41.2 & - & 81.8 & 9.1 & 30.4 & 43.8 \\
\hline $\mathrm{A} 2$ & 52.1 & 46.8 & 5.8 & 45.3 & - & 90.2 & 6.2 & 17.0 & 71.1 \\
\hline A3 & 54.7 & 48.3 & 8.5 & 36.7 & - & 87.1 & 7.3 & 26.3 & 55.3 \\
\hline A4 & 55.3 & 50.2 & 8.7 & 39.3 & - & 88.8 & 7.3 & 17.9 & 66.7 \\
\hline A5 & 55.7 & 52.0 & 8.1 & 34.3 & - & 68.8 & 7.2 & 28.9 & 51.4 \\
\hline A6 & 55.4 & 47.7 & 8.2 & 29.7 & 56.0 & 78.6 & 12.8 & 35.0 & 39.6 \\
\hline A7 & 45.6 & 44.7 & 6.6 & 38.3 & 62.0 & 89.1 & 6.9 & 21.3 & 64.0 \\
\hline A8 & 55.4 & 47.3 & 8.2 & 47.4 & - & 89.2 & 6.3 & 22.2 & 59.3 \\
\hline A9 & 52.6 & 48.3 & 9.7 & 39.1 & - & 88.9 & 7.4 & 21.9 & 55.7 \\
\hline A10 & 54.9 & 52.9 & 7.5 & 47.7 & - & 70.8 & 7.8 & 36.9 & 41.9 \\
\hline A11 & 48.0 & $46.7 / 46.0$ & 7.0 & $47.9 / 39.2$ & $47.1 / 58.0$ & 80.8 & 12.9 & 35.1 & 33.0 \\
\hline A12 & 51.2 & 49.9 & 8.0 & 43.9 & - & 77.8 & 15.5 & 35.3 & 31.6 \\
\hline A13 & 45.0 & 45.5 & 6.4 & 33.7 & - & 82.2 & 8.8 & 30.0 & 53.4 \\
\hline
\end{tabular}

Table 6 Comparison of pore structures analysis by different methods

\begin{tabular}{|c|c|c|c|c|c|c|c|}
\hline \multirow{2}{*}{$\begin{array}{l}\text { Sample } \\
\text { number }\end{array}$} & \multicolumn{5}{|c|}{ Mercury porosimetry method } & \multicolumn{2}{|c|}{ Image analysis method } \\
\hline & $\begin{array}{l}\text { Bulk } \\
\text { density }\end{array}$ & $\begin{array}{l}\text { Apparent } \\
\text { density }\end{array}$ & $\begin{array}{l}\text { Mean radius } \\
(\mu \mathrm{m})\end{array}$ & $\begin{array}{l}\text { Sp. pore vol } \\
\left(\mathrm{mm}^{3} / \mathrm{g}\right)\end{array}$ & $\begin{array}{l}\text { Sp. pore surface } \\
\left(\mathrm{m}^{2} / \mathrm{g}\right)\end{array}$ & $\begin{array}{l}\text { Mean pore wall } \\
\text { thickness }(\mu \mathrm{m})\end{array}$ & $\begin{array}{l}\text { Average } \\
\text { roundness }\end{array}$ \\
\hline A1 & 1.3000 & 2.2123 & 34.37 & 317.2 & 2.549 & 156.3 & 2505.0 \\
\hline $\mathrm{A} 2$ & 0.9639 & 1.7617 & 27.47 & 469.8 & 6.608 & 210.2 & 4671.0 \\
\hline A3 & 0.9634 & 1.5220 & 27.96 & 381.0 & 8.543 & 173.0 & 2577.0 \\
\hline A4 & 1.0419 & 1.7150 & 28.25 & 376.7 & 4.213 & 204.0 & 2446.0 \\
\hline A5 & 1.0675 & 1.6247 & 41.45 & 321.3 & 5.413 & 144.0 & 2294.0 \\
\hline A6 & 1.1636 & 1.6546 & 42.03 & 255.0 & 4.532 & 135.0 & 2547.0 \\
\hline A7 & 1.1512 & 1.8661 & 37.48 & 332.8 & 2.727 & 175.0 & 2967.0 \\
\hline A8 & 0.7999 & 1.5193 & 31.14 & 497.8 & 3.515 & 168.0 & 3808.0 \\
\hline A9 & 1.0389 & 1.7056 & 27.46 & 376.3 & 8.195 & 188.0 & 3068.0 \\
\hline A10 & 0.6804 & 1.3009 & 28.02 & 700.9 & 14.841 & 137.0 & 2271.0 \\
\hline A11 & 1.0773 & 1.9251 & 29.00 & 403.9 & 5.603 & 150.0 & 2669.0 \\
\hline A12 & 1.2995 & 2.3152 & 27.41 & 337.6 & 1.902 & 147.0 & 3029.0 \\
\hline A13 & 1.0659 & 1.6077 & 26.91 & 316.1 & 6.027 & 138.8 & 3618.0 \\
\hline
\end{tabular}

taken for the image analysis. The variation in coke properties such as, $\mathrm{M}_{40}, \mathrm{M}_{10}, \mathrm{CRI}$ and $\mathrm{CSR}$ value ranges between 68.8 to $90.2 \%, 6.2$ to $15.5 \%, 17.0$ to $36.9 \%$ and 31.6 to $71.1 \%$, respectively. Results of experimental analysis are presented Table 5.

Polished section of coke samples were prepared by $1 \mathrm{~mm}$ size coke particle. The image analysis method shows total area, length, perimeter, roundness, pore-wall thickness and porosity (vol\%) of each sample. Porosity values of coke samples varied from 45.5 to $52.9 \%$ with standard deviation between 5.8 and 9.9 (Table 5) was observed in image analysis method. For each coke samples, 20 numbers of frames have been captured and it was found that the porosity values varied from 21.7 to $67.5 \%$ in most of the coke sample during image analysis method.

Analysis shows that pore structure has significant control on cold and hot strength properties of coke samples. As the porosity decreased the number of pores will be decreased, which resulted in increase in $\mathbf{M}_{40}$ index and hence CRI and CSR values improved. In case of mean pore-wall thickness, the result shows a good correlation between cold and hot strength parameter of coke quality. 
The pore wall thickness measurement (Table 6) by image analysis provided significant correlations with $\mathrm{M}_{40}$, CRI and CSR values (Figs. 4, 5a, b). Figure 4 shows relationships between mean pore wall thickness and $\mathrm{M}_{40}$ index linearly proportion with some extent. From this figure, it was also found that the pore wall thickness increase the $\mathrm{M}_{40}$ index at some extent with other factors is attributed for the $\mathrm{M}_{40}$ index. Coke samples A2, A4, A7, A8 and A9 shows increase trend with pore wall thickness and $\mathrm{M}_{40}$ index due to use of low volatile matter (VM), sufficient dilatation with good plastic range coal in carbonization. Coke samples A5, A6, A10, A11 and A12 Shows decrease pattern along with pore wall thickness and $\mathrm{M}_{40}$ index. Both the pore wall thickness and $\mathrm{M}_{40}$ index was found lowest in these samples. This was happened due to use of high VM and insufficient dilatation coal used in carbonization. So, it was observed that coke produced from high VM and insufficient dilatation coal was less strength (thin pore wall thickness) as compared to low VM coal blend. As the porewall thickness increased, improvement in $\mathrm{M}_{40}$ index, CRI and CSR was observed. Moreover, accordingly Fig. 5a shows A2, A4, A7, A8 and A9 samples have lowest CRI value and samples A5, A6, A10, A11 and A12 shows maximum CRI value. The pore wall thickness of coke sample A2, A4, A7, A8 and A9 also shows maximum value rather than coke sample A5, A6, A10, A11 and A12.

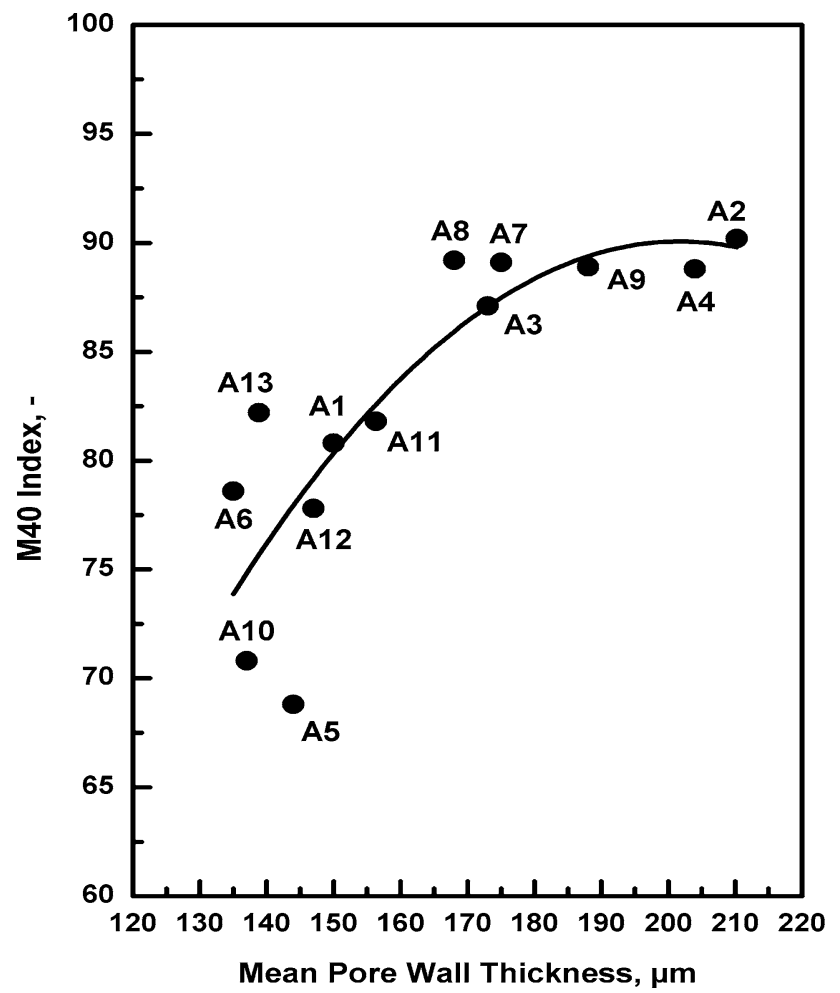

Fig. 4 Relationship between mean pore-wall thickness and $\mathbf{M}_{40}$ index
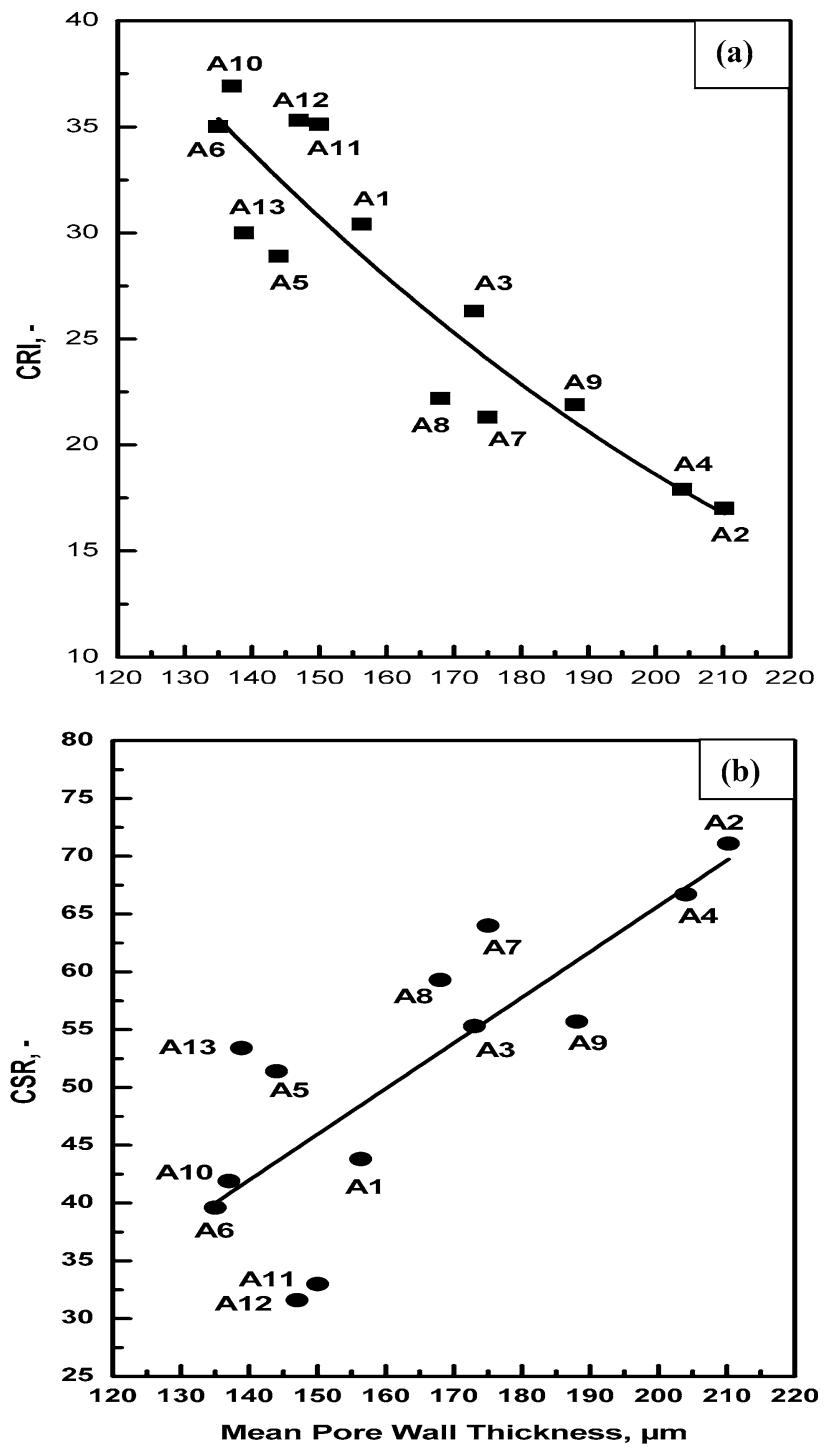

Fig. 5 a Relationship between mean pore-wall thickness and CRI, b relationship between mean pore-wall thickness and CSR

Figure $5 \mathrm{~b}$ shows the relationship between mean pore wall thickness and CSR. It was observed that A5, A6, A10, A11 and $\mathrm{A} 12$ samples have lowest CSR value as compared to A2, A4, A7, A8 and A9 samples. Mean pore wall thickness also shows high in $\mathrm{A} 2, \mathrm{~A} 4, \mathrm{~A} 7, \mathrm{~A} 8$ and $\mathrm{A} 9$ samples rather than the A5, A6, A10, A11 and A12 samples. The porosity values of A2, A4, A7, A8 and A9 of coke sample were $46.8 \%, 50.2 \%, 44.7 \%, 47.3 \%$ and $48.3 \%$, respectively. The porosity values of A5, A6, A10, A11 and A12 of coke sample were $52.0 \%, 47.7 \%, 52.9 \%, 46.7 \%$ and $49.9 \%$, respectively. It can be concluded that for a good coke with high CSR and low CRI means to produces coke with low porosity, more numbers of sample pores and increase in the pore wall thickness.

It was found that the increase in roundness of pores improved the porosity (Fig. 6a). Also average of roundness 
of pores was measured by the image analysis method and provided good correlations with $\mathrm{M}_{40}$, CRI and CSR values (Figs. 6b, 7a, b). The pore wall thickness and average roundness of pores have shown a good correlation with $\mathrm{M}_{40}$ index, CSR and CRI. At certain limit, increases in the pore wall thickness and average roundness of pores have shown improvement in coke quality. The pore wall thickness and average roundness of pores have significant role for the BF coke making. High VM coals were used in carbonization shows high porosity values with lower pore roundness with low-circularity of pores (connected pores) is shown in Fig. 3a. Coke samples A2, A4, A7, A8 and A9
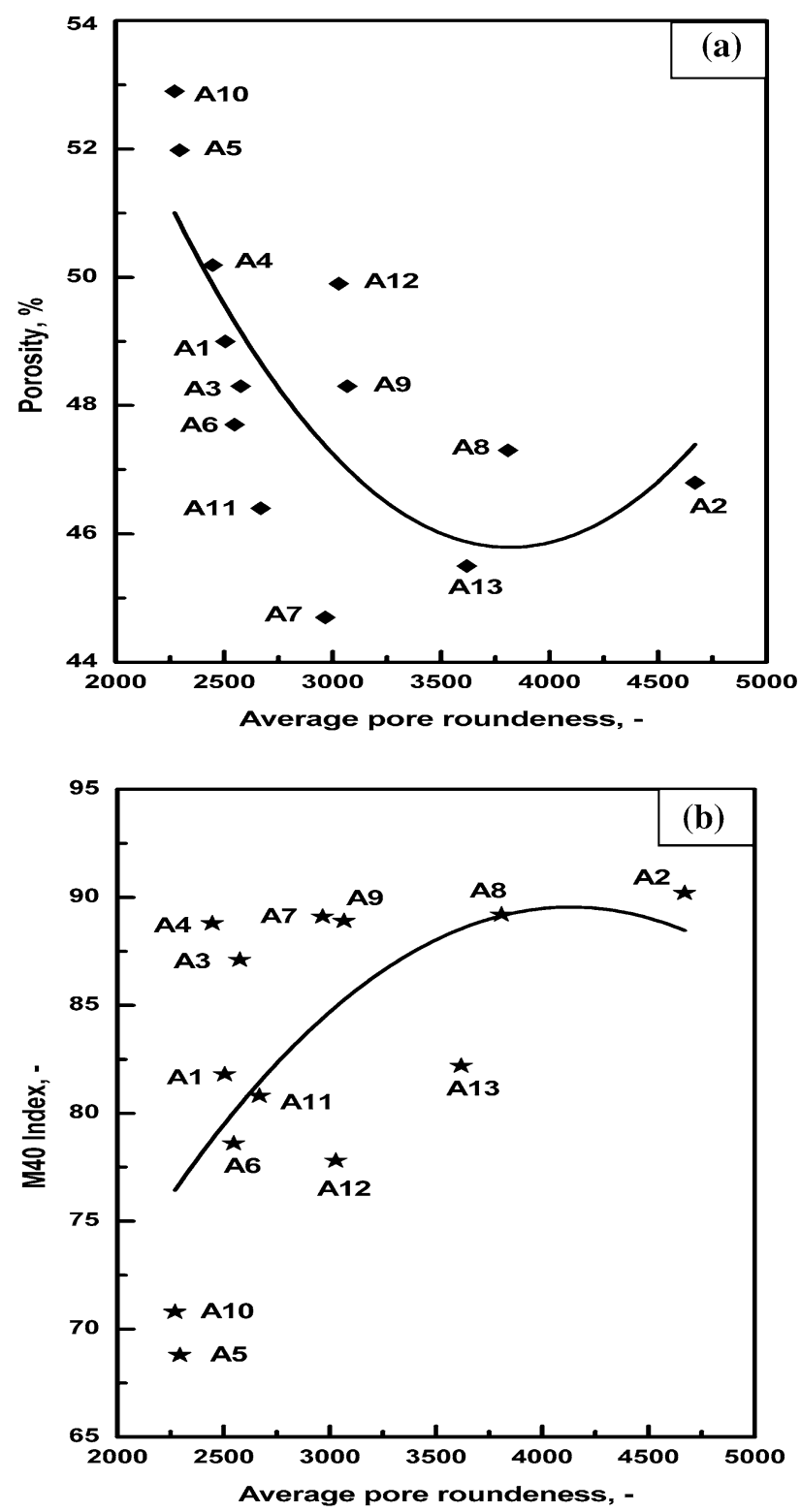

Fig. 6 a Relationship between average roundness of pores and porosity \% (image analysis), b relationship between average roundness of pores and $\mathrm{M}_{40}$ index
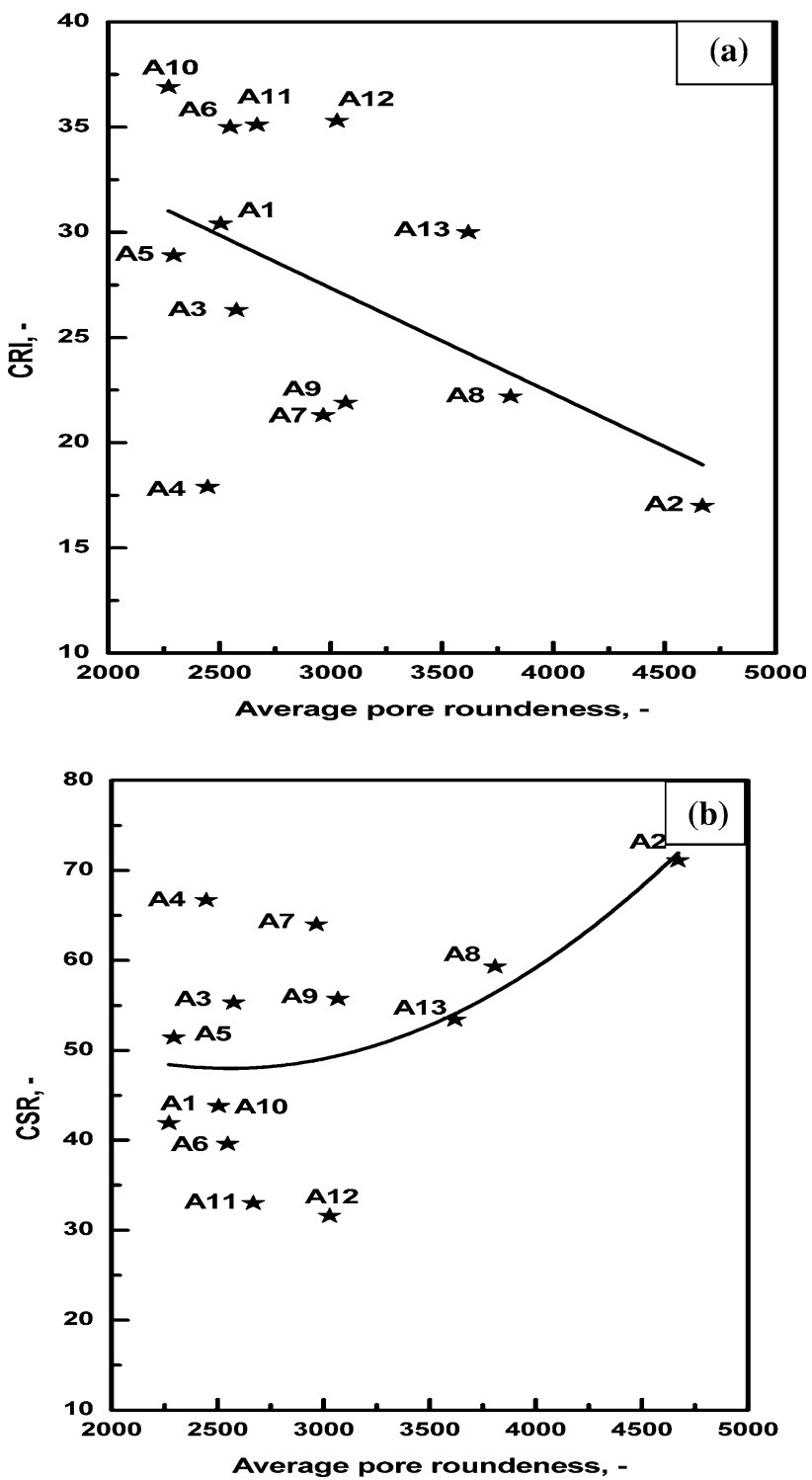

Fig. 7 a Relationship between average roundness of pores and CRI, b relationship between average roundness of pores and CSR

were formed with high-circularity pores rather than samples A5, A6, A10, A11 and A12 (Figs. 6b, 7a, b). Lower pore roundness (low-circularity) coke has prone to less strength and prone to development of crack in coke. Lower- circularity cokes are formed due to thermo mechanical behaviors of coal particles, dilatation and rank of coal. Insufficient dilatation coals blended were used in coke samples A5, A6, A10, A11 and A12. As a result, volume of coal expansion is smaller than that of interparticle spaces. In this case, dilating coal particles undergo free dilatation and thus foams in coal particles connect to the other foams with thinning foam films. Otherwise, foams connect to inter-particle spaces because foam films break. For this reason, the diffusion of gas trapped within the 
foams is facilitated and foams fail to maintain growth, thus the dilatation of particles terminates. As a result, coals are solidified as in a maintained form under which foams are burst and such pores connected with the multiple pores as in the region encircled with a line in Fig. 3a, meaning socalled connected pores are formed. A2, A4, A7, A8 and A9 were used sufficient dilatation coals blend; volume of coal expansion is higher than the inter-particle space. In this case, with thinning foam film does not occur in these blend and straight coal.

\subsection{Coke structure analysis by volumetric, mercury porosimetry and $X$-ray computed tomography} (ct) scan method

The porosity of coke, which is calculated from the true and apparent densities, is one of the quality parameters of this coke type. At first the real and apparent density was measured by these methods. From these density measurements, the percentage porosity has calculated using the following relation: porosity $(\%)=100[1-$ (apparent density/true density)]. The mercury porosimeter consists of two units, PASCAL 140 is an automatic instrument for the sample preparation for the porosimetric analysis and measures porosity in the ultra macro and macro pores

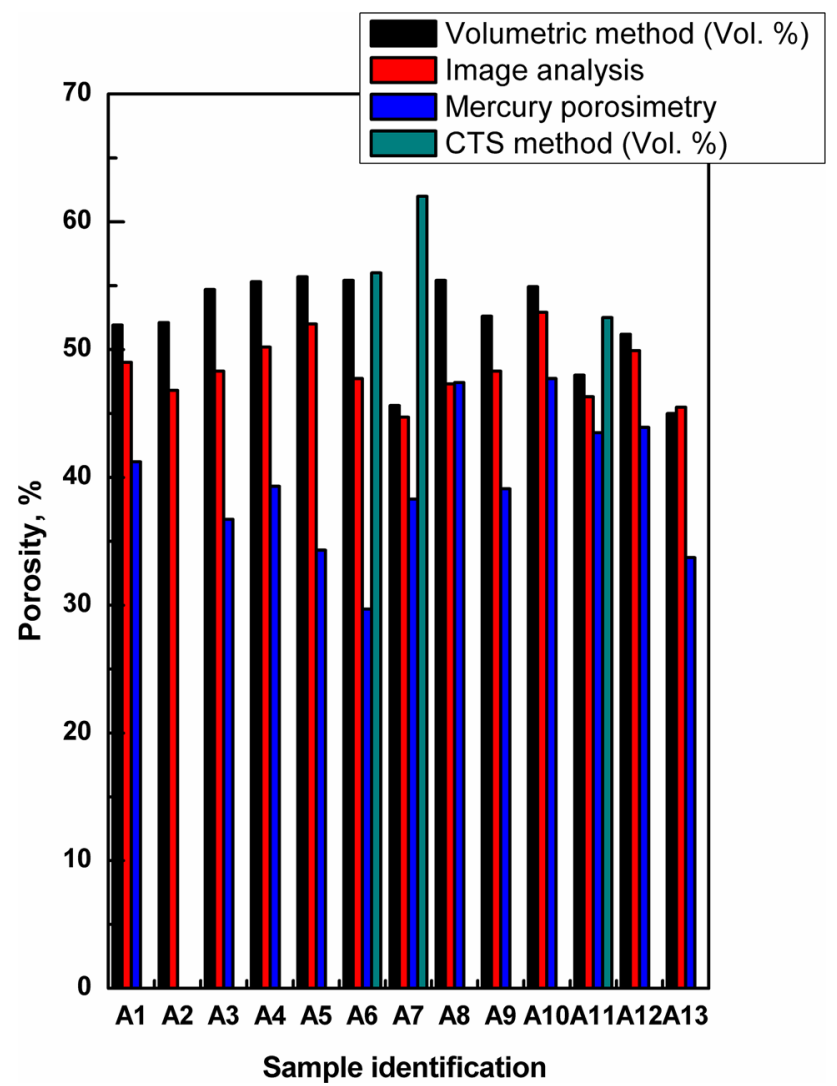

Fig. 8 Comparison of porosity values by different methods regions $(1900-58000 \mathrm{~nm})$ by exerting maximum pressure of $400 \mathrm{kPa}$ and PASCAL 440 measures the pore radius in the range of 1.8-7500 $\mathrm{nm}$ by means of mercury intrusion at high pressure of $400 \mathrm{MPa}$ and pore volume in the range of $0.1-500 \mathrm{~mm}^{3}$. The measuring principle is based on the non wetting characteristics of mercury with lot of solid materials. The mercury surface tension and contact angle with the solid material are constant during analysis. The pore radius is inversely proportional to the applied pressure according to Washburn equation;

$D=\left(\frac{-4 \gamma \cos \theta}{P}\right)$
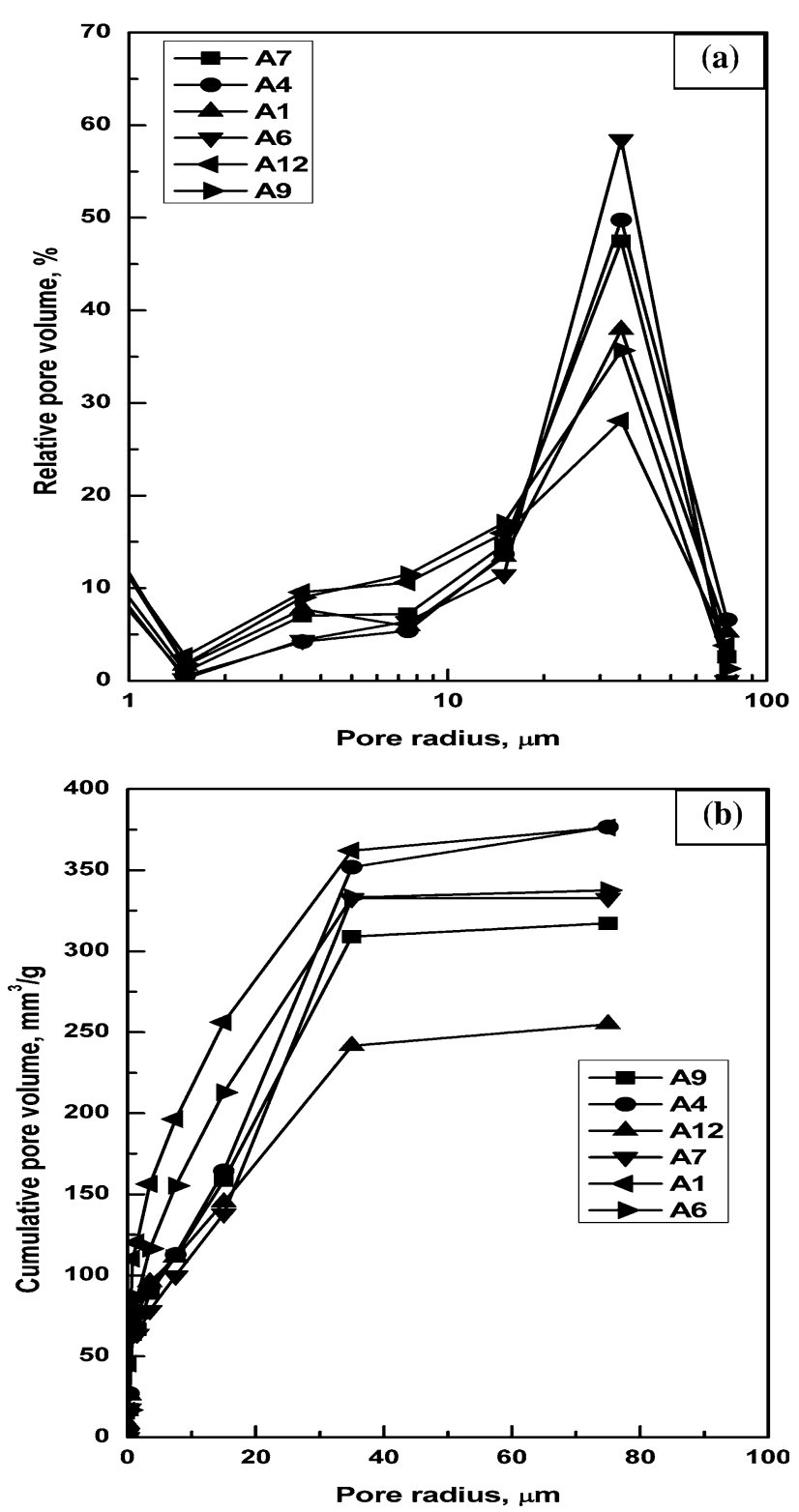

Fig. 9 a Plot of relative pore volume versus pore radius, $\mathbf{b}$ variation of cumulative pore volume with pore radius 


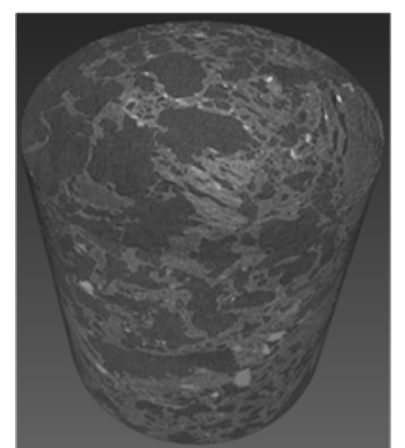

3D Raw Scanned Image

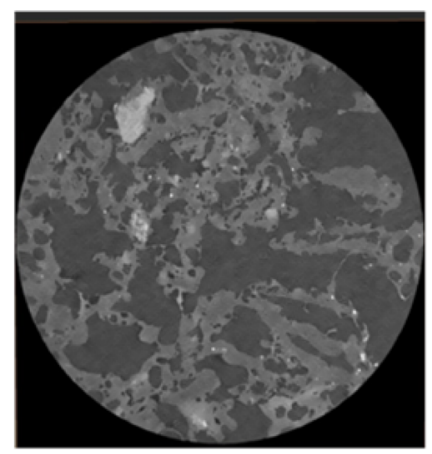

2D Image

(grey region in circle =solid part)

(black region in circle $=$ pores)

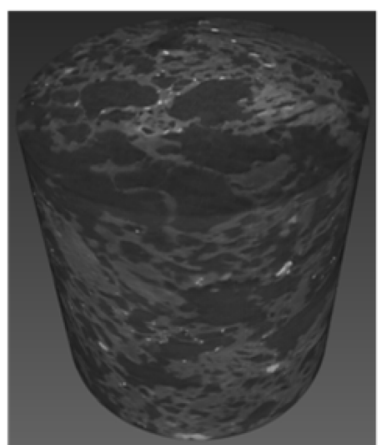

3D Image after

adding median filter

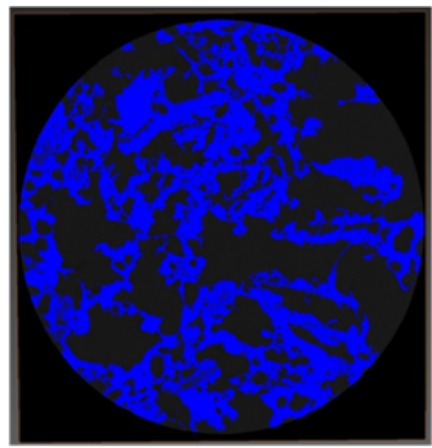

Selection of solid part

(grey region)

\section{Volume fraction of \\ solid part $=0.42$; Hence \\ porosity is $58 \%$}

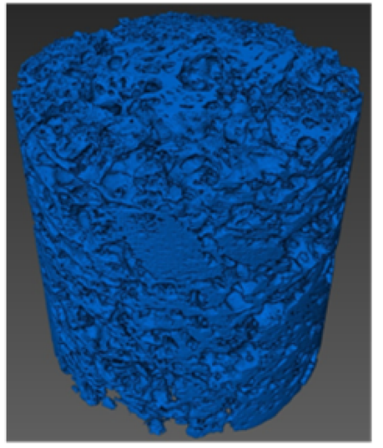

3D Image after segmentation of solid part

Fig. 10 X- ray computed tomography showing pore size distribution in coke samples

where, $D=$ Pore diameter, $\gamma=$ Surface tension of intrusion liquid, $\theta=$ Contact angle of liquid with pore wall and $P=$ Absolute applied pressure. By measuring the quantity of mercury penetrated on the sample pores at equilibrium pressure at which intrusion occurs, experimental data are obtained to calculate the pore volume distribution as a function of their radius. The operation of the equipment is controlled by software compatible to WINDOWS NT programme. It provides information about pore volume distribution for porous materials through computerized data analysis. Coke structure analyzed by the volumetric method, mercury porosimetry, image analysis and CT scan method were given in Tables 5 and 6. Thirteen numbers of coke samples were analyzed in volumetric method, mercury porosimetry, image analysis and four numbers of samples were analyzed by X-ray CT scan method (Fig. 8). Mercury porosimetry methods determined the pore size distribution, pore volume, relative volume and relative surface of pores. A plot of relative pore volume versus pore radius for six numbers of coke samples is given in Fig. 9a. From the plot, it is clear that all the coke samples have average pore radius $(35 \mu \mathrm{m})$. The variation of cumulative pore volume with pore radius is shown in Fig. 9b. The total cumulative volume and specific surface area of all coke samples have different values. In all the cases the maximum relative volume percentages of pores are in the ranges of $20-50 \mu \mathrm{m}$.

CT-Scan allows accurate and detail study for morphometry and densitometry. Powerful, flexible and programmable image processing tools allow a wide range of segmentation, enhancement and measurement functions for analyses ranging from porosity to contact surface around high density insertions to complex architectures. Figure 10 shows X-ray computed tomography of coke sample given 3-D view of pore network along with pore size distribution. Mercury porosimetry method signified the porosity value ranges from 29.7\% (A6 sample) to $47.9 \%$ (A11 sample) and pore size distribution of $20-50 \mu \mathrm{m}$. The repeatability test for coke sample A11 was carried out and porosity values were found as $47.9 \%$ and $39.2 \%$. It shows that the mean value obtained was not in good within $8.7 \%$ range. $\mathrm{X}$-ray CT scan method signified the porosity value ranges from $47.1 \%$ (A11 sample) to $62.0 \%$ in A7 sample. The repeatability test for coke sample A11 was carried out and porosity values were found as $47.1 \%$ and $58.0 \%$. It shows that the mean value was not in good within $10.9 \%$ range. Volumetric method shows porosity ranges varied from $45.6 \%$ in A7 sample and $55.7 \%$ in A5 sample. Volumetric 
method determined the average porosity values of the coke samples. The limitation of this method was that the measurement of coke structure parameters like pore size distribution, shape of pore and pore-wall thickness was not possible. Both the Mercury porosimetry and X-ray CT scan methods used single pieces of coke sample rather than crushed sample. Therefore, determinations of coke structure from these methods were varied from sample to sample. It shows the limitation of representatives of sample.

\section{Conclusions}

Porosity measurement by volumetric method provided average porosity values and thus poor correlations with $\mathrm{M}_{40}$, CRI and CSR. However, porosity determined by image analysis provided average porosity in addition to pore-wall thickness and roundness of pores. The values of porosity were comparable with values measured by volumetric method. Additionally it provided better correlation with $\mathrm{M}_{40}$ index as compared to porosity by volumetric method. The pore wall thickness measurement by image analysis provided significant correlations with $\mathrm{M}_{40}$, CRI and CSR values. This explains the usability of image analysis for coke structure measurement. A comparative study was carried out for measurement by volumetric method, image analysis, mercury porosimetry and X-ray CT scan measurements. It showed limitation of representatives of coke sample against the measurement of mercury porosimetry and CT scan measurement as these methods use single piece not the crushed sample. Pore wall thickness affects $\mathrm{M}_{40}$ index, CRI and CSR and this can be determined only by image analysis. High VM with insufficient dilatation coals were used in carbonization shown high porosity values with lower pore roundness (high lowcircularity of pores: connected pores).

Acknowledgements The authors are very much thankful to the management of RDCIS, SAIL, Ranchi for their financial grant to carry out the present research work.

Open Access This article is distributed under the terms of the Creative Commons Attribution 4.0 International License (http://crea tivecommons.org/licenses/by/4.0/), which permits unrestricted use, distribution, and reproduction in any medium, provided you give appropriate credit to the original author(s) and the source, provide a link to the Creative Commons license, and indicate if changes were made.

\section{References}

Andriopoulos N, Loo CE, Dukino R, McGuire SJ (2003) Microproperties of Australian coking coals. ISIJ Int 43:1528-1537

Bhattacharyay D, Kocaefe D, Kocaefe Y, Morais B (2013) Determination of coke, pitch and pores/cracks in green anode by image analysis. J Surf Eng Mater Adv Technol 3:1-6

Das TK, Mishra S, Ghosh KN, Ghosh NK (2009) Role of coke optical texture in explaining mysterious behavior of coke. In: Proceedings of international conference on coking coals and coke making: challenges and opportunities, Ranchi, pp 401

Donskoi E, Poliakov E, Lu L (2013) Advances in optical image analysis of coke structure. In: 10th Australian coal science conference, Brisbane, Queensland

Eberli GP, Baechle GT, Weger R, Massaferro JL (2004) Quantitative discrimination of effective porosity using digital image analysisimplications for porosity-permeability transforms, 66th EAGE conference, Paris

Eilertsen JL, Rrvik S, Foosns T, Øye HA (1996) An automatic image analysis of coke texture. Carbon 34:375-385

Grant MGK, Chaklader ACD (1991) Factors affecting the strength of blast furnace coke. Fuel 70:181-188

Greeff SC, Smith WH (1987) Automated coke petrography, APCOM 87 , proceeding of the 20th international symposium on the application of computers and mathematics in the mineral industries, metallurgy, SAIMM, Johannesburg, vol 2, pp 253

Gupta S, Shen F, Lee WJ, O'Brien G (2012) Improving coke strength prediction using automated coal petrography. Fuel 94:368-373

Hayashi Y, Aizawa S, Uebo K, Nomura S, Arima T (2014) Evaluation of coal thermoplastic and dilatation behavior with coke pore structure analysis. ISIJ Int 54:2503-2511

Johnson DW, Sherborne C, Didsbury MP, Pateman C, Cameron NR, Claeyssens F (2013) Macrostructuring of emulsion-templated porous polymers by $3 \mathrm{D}$ laser patterning. Adv Mater 25:3178-3181

Karacan CO, Badger M (2003) Effect of steam injection on pore structure and distribution in coke samples produced by delayed coking. Fuel 82:909-917

Kubota Y, Nomura S, Arima T, Kato K (2011) Quantitative evaluation of relationship between coke strength and pore structure. ISIJ Int 51:1800-1808

Menendez JA, Alvarez R, Pis JJ (1999) Determination of metallurgical coke reactivity at INCAR: NSC and ECE-INCAR reactivity tests. Ironmak Steelmak 26:117-121

Nyathi MS, Mastalerz M, Kruse R (2013) Influence of coke particle size on pore structural determination by optical microscopy. Int $\mathrm{J}$ Coal Geol 118:8-14

Patrick JW, Walker A (1989) Macroporosity in cokes: its significance, measurement, and control. Carbon 27:117-123

Qiao GL, Eser S (1997) Digital image analysis of optical texture and porosity of petroleum cokes. The Pennsylvania state university, University park, p 933

Radlinski AP, Mastalerz M, Hinde AL, Hainbuchner M, Rauch H, Baron $M$ et al (2004) Application of SAXS and SANS in evaluation of porosity, pore size distribution and surface area of coal. Int J Coal Geol 59:245-271

Sato H, Patrick JW, Walker A (1998) Effect of coal properties and porous structure on tensile strength of metallurgical coke. Fuel 77:1203-1208

Xing X, Zhang G, Rogers H, Zulli P, Ostrovski O (2013) Coke microstructure and strength under blast furnace conditions. In: 10th Australian coal science conference proceedings. Australian Institute of Energy, Australia, pp 1 